\title{
Erratum to: Reduced expression of MyHC slow isoform in rat soleus during unloading is accompanied by alterations of endogenous inhibitors of calcineurin/NFAT signaling pathway
}

\author{
Yulia N. Lomonosova $^{1} \cdot$ Olga V. Turtikova $^{1} \cdot$ Boris S. Shenkman ${ }^{1}$
}

Published online: 7 December 2015

(C) Springer International Publishing Switzerland 2015

\section{Erratum to: J Muscle Res Cell Motil DOI 10.1007/s10974-015-9428-y}

The acknowledgement section was missed inadvertently in the above mentioned article. The acknowledgement is provided in this Erratum.

\begin{abstract}
Acknowledgments The authors are extremely grateful to Professor S. Labeit (Mannheim, Germany) for kindly providing antibodies against MuRF-1 and MuRF-2. We also express our gratitude to Anton Pokusaev and Alexandra Minailova who helped us in processing of biological samples. The work was supported by a grant of the Russian Science Foundation, No 14-15-00358.
\end{abstract}

The online version of the original article can be found under doi:10.1007/s10974-015-9428-y.

Boris S. Shenkman

bshenkman@mail.ru

1 Institute of Biomedical Problems, Russian Academy of Sciences, 76a, Khoroshevskoe Shosse, Moscow 123007, Russia 